\title{
CONSERVATION AS A WORLD PROBLEM
}

\author{
By Professor W. H. Pearsall, F.R.S.
}

One of the most important aspects of the conservation of nature is its relation to a world problem : that of producing food and raw material in quantities sufficient to balance increases in population. This problem may, of course, be considered from various points of view. I shall consider it mainly from the point of view of an ecologist, starting from the fact that because the amount of highly productive land under cultivation is diminishing rather than increasing, it will be necessary to turn to regions at present marginal or undeveloped in order to produce any considerable increase in production.

Over the almost immeasurable past, the organisms, plant and animal, present in a natural vegetation cover have become closely adapted to life under the environmental conditions they live in. The penalty for lack of fitness to fall in with the conditions of the habitat, and of life in competition with the other plants and animals in the community, is elimination.

At first, man also was a creature of his environmenta hunter or a trapper-incidentally one learning to conserve the animals he depended on, and little difficulty arose from his presence. The first forms of human agriculture were hardly more destructive: small areas of shifting cultivation that used the stored fertility of the soil and then moved on, allowing the natural vegetation, usually forest, to return and restore the original condition. In Western Europe, that era is long past; it happened so long ago that it is only with the greatest difficulty that we can now reconstruct the original vegetation-almost always forest. Now we have reached the stage when human populations are becoming so large and are increasing so rapidly that little more of the earth's surface remains undisturbed, while demands for food and raw materials are increasing at an astronomical rate. Under these circumstances, the condition of the earth's surface and also of the balance of nature, so far as it can exist, are going to be controlled entirely by human activity, and it would be well to ask where this will lead us. It is this sort of world problem that ecologists have to face and it may be of interest to consider how they look at it.

In the first place, in the long-cultivated parts of the earth's surface, a series of new balances of nature have been established, which, by and large, have been subject to the same laws of the 
elimination of the unsuitable, as those that operate in purely natural surroundings. These are the major systems of agriculture, such as those in Western Europe, in the United States and elsewhere, most of them occupying climates that are not in any way extreme and depending on soils that are relatively productive. As demands have increased, these systems have tended more and more to become replacement systems, the materials taken from the environment being returned by irrigation or manurial treatment. As the treatments have become more intensive and costly, less and less of the earth's surface has remained in these highly productive systems and more has become marginal. The parts of the earth's surface left under more natural vegetation and still offering possibility for the extension of food and raw material production, are those that, in some obvious respect, such as seasonally unsuitable climate, are not easy to cultivate, or else they lie on soils that on trial are quickly found to become unproductive.

It is clearly folly to suppose that traditional methods of agriculture, which have been successful in other environments, can be equally successful in these different conditions, nor is it likely that it will be cheap to utilize the marginal habitats; they are almost certain to be very expensive to develop as productive units, because initial treatment would be necessary to overcome the inherent difficulties. Particularly, for example, it is unlikely that methods suitable for Western Europe will be equally suitable in tropical Africa. An illustration of this from recent history, the ground-nuts scheme, will occur to many.

Another feature seems to be particularly marked in these marginal and undeveloped lands. It appears to be the rule that the slow natural development of the plant and animal community has resulted finally in a balanced condition, which gives the maximum productivity possible in that site. When we disturb this condition of balance, we are likely, so far as we at present know, to produce a less productive and unbalanced condition, so that expensive measures are required to remedy the new and disturbed state of affairs. This has been a familiar problem in the more arid parts of the warmer climatic zones. There, it has been common practice to try to turn the more open forests and bush-land into cattle ranches or even into arable cultivation. The changes thus initiated result in the destruction of the woodland and there follows a hardening of the soil surface so that rain runs off where formerly it sank into the soil. A lowering in the production level results, and a regular rake's progress is observed to follow. The original woodland normally contained 
wild grazing animals ; this gives place to treeless cattle ranches with further compaction of the soil surface. As the range of vegetation cover declines in weight, sheep are introduced to replace the cattle, because they can graze more closely and on poorer herbage. Further deterioration follows, ultimately leading to a habitat and vegetation so near to desert as to be capable of supporting only random grazing by goats and camels. It is known that this sequence has been followed in vast areas of the Middle East, North Africa and India, which are now in desert or semi-desert condition. Nevertheless, the same methods of development are being widely advocated and used to-day elsewhere in Africa and America, where similar changes are ensuing.

In Britain our marginal lands have shown similar cycles of deterioration. They are subject to what the ecologist calls "trends" of change. The damp climate causes the washing away of essential plant foods. The destruction of the original rather open woodlands on what are to-day marginal lands, accelerated this process and at the same time allowed a good deal of soil crosion, and there is satisfactory evidence that the soils and vegetation of these areas have lost a great deal of their original productivity. The redevelopment of productivity in these areas will involve, therefore, a very large-scale operation, because in one form or another they amount to nearly a quarter of the whole area of Britain.

I use these examples as illustrations of the fact that the vegetation and animal life on the remaining marginal and undeveloped areas is generally very sensitive to disturbance ; after disturbance the habitats are particularly subject to rapid deterioration. It would be easy to adopt a negative attitude to this problem and say that most of these areas should remain untreated. We must, however, face the fact that most of the earth's surface will need to be more productive if food and raw material are to be provided for increasing populations. So we may also ask what should be the ecologist's way of tackling this type of problem. An ecologist would, I think, first like to see land classified according to its best possible or potential uses ; our American friends call this drawing up a "land capability classification". Undoubtedly this type of survey should first take into account whether the land is primarily suitable for the production of protein, that is meat, milk, wool or hide, or for the less exacting needs of carbohydrate formation, wood, fibres such as cotton, flax, hemp and so on. The levels of production possible would no doubt vary within each group and it would 
follow that the development of any area would take into account the potentialities as revealed in the classification. In this way it might be possible to avoid the conflict of opinion over what is meant by production. The hill farmer is likely to think of production only in terms of numbers of sheep, while the forester would consider only trees.

Secondly, I think that the ecologist would like to set aside very considerable areas of undeveloped country for study and experiment. We could call them, if you like, nature reserves, as we do in Britain, or national parks, as they do in Africa. They are wanted in the first place for the scientific study of the natural plant and animal species and populations. But though very valuable scientific results may be expected to come from such studies, from our present point of view we particularly want to know all we can about the balances between the different types of organisms and their inter-relations with the habitat. In short, the trends in these populations and their habitat, particularly in their relations with and effects on soil and water.

Thirdly, however, ecologists would like, as scientists, also to be able to use these areas to carry out experiments. The contribution of science to human progress has not been solely the integration of knowledge and the discovery of new facts. The major contribution to human thought has been the introduction of the experimental method, the testing of a hypothesis by experiment designed to determine the effect of a different treatment. Because of the danger in the case of our marginal lands of damage to their productivity by disturbance, and because it is reasonably certain that most of them will raise new problems that have not been tackled in the more settled part of the earth's surface, it is important that the approach to what should be done should be an experimental one; to try first on a small scale and to see what the effects produced are likely to be. We want to know not only whether an acre of land will produce three or four thousand pounds of dry grass or heather, or if grazed, half a sheep, or if under pine trees, ten thousand pounds of pit props. We want to know also what will be the effect of these forms of production on the water supply and particularly on soil ... the capital on which production depends. Moreover, we need to verify even the primary hypothesis that production may well be highest in such places in a natural or balanced plant and animal community. This is at present a matter of inference; if it is true it may well mean that we ought to envisage maintaining these natural communities in some form or other and of devising methods of exploiting them. 
A problem of this sort, which is now prominent, is that of the possible development of land at present occupied by large herds of herbivorous animals, caribou in the arctic, wildebeest, zebras and plains-game of various sorts in Africa, and no one who has seen these creatures in their abundance will doubt the desirability of preserving some, at least, of them for the future. This is no doubt an amenity interest, but with as much to commend it on scientific grounds as on sentimental grounds. The. animals are, however, migratory, often with a range extending over hundreds of miles. In one African example, which has been studied in some detail, an area of some two or three thousand square miles will be required to safeguard their habitat and their existence in reasonable numbers. It is easy to say: make this a nature reserve, but a land-hungry world may well take a contrary view and say that the animals should be preserved in zoos. To the ecologist, the problem here is that of preserving for study the whole grouping of plants and animals, including predators, that are found in the areas they occupy. There is much that can be learnt from studying these groupings, not least the reason why these wild animals are usually found in magnificent condition while cattle kept by natives in the same areas are equally often in poor condition. Here is a case where the competent authorities believe that the natural grouping of plants and animals is more productive, in protein foods for example, than any development that has yet been tried on this type of country, and hence the best use of such land may be to maintain the status quo along with some system of controlled hunting.

There is thus a strong case for making large reserves for game preservation, if we realize these are not only to preserve the animals concerned, but also to maintain their natural range of habitats for study, to solve the problem of how a natural balanced group of organisms can be productive under rather adverse condition. Such areas might well be expected to throw light on the possibilities of future land use and on the effects of possible types of treatment upon the vegetation cover and the soil and water conditions that are found there.

It seems, therefore, that any civilized state with large areas of undeveloped or marginal territory must accept the need to set aside suitable areas where the original balance of nature can be studied and where hypotheses concerning its characteristics and its possible modification can be put to the test. It matters little what we call these areas-nature areas or conservation areas-as long as we recognize their function. This is not 
simply to preserve things, conditions and beings, that might otherwise vanish, but to enable us to integrate them, to learn from them and so put the lessons to be learnt to future use. In short, we are less concerned with preserving the past and putting the clock back and more interested in acquiring the knowledge that will enable us to push our thoughts and ideas forward. Above all, perhaps, we must recognize that the balance of nature in the future will be largely man-controlled. We shall, as a result, get the sort of world which we ourselves develop.

Many years ago, W. G. Collingwood said, of one of the most beautiful parts of Britain, the English Lake District, that its beauty was the result of a thousand years of human occupation. Here is an idea to remember. These amenities, both for mind and for body, are as important as is material production, in marking the progress of mankind.

Note.-The above article was one of a series of talks given on the B.B.C. Third Programme, entitled "Living Heritage : The Balance of Nature ". Producer. Dr. A. Clow. 